\title{
Study on Exploration and Practice of Comprehensive Arts Experiment Teaching*
}

\author{
Tiejun Wang \\ Academy of Fine Arts \\ Northeast Normal University \\ Changchun, China 130024
}

\begin{abstract}
Experimental model of teaching comprehensive arts, methods of study to become teachers in art university the key aspects of educational practice level, combined with teaching and social cooperation experiment results show, set to deepen the reform of the teaching experiment, the establishment of "broaden the base, optimize resources, emphasis on curriculum scientific evaluation of the combination", the idea of college training, building science, research, and creating an integrated experimental teaching model, follow the experience of discovery-explorationinnovation and the importance of experimental philosophy.
\end{abstract}

Keywords-comprehensive arts; experimental teaching; research and practice

\section{INTRODUCTION}

New meaning in space, people environmental awareness has been awakened, the increasing demand for integrated arts $[1,2]$. Living environment to promote art, emphasizing the improvement and creation of environment, the public nature of the modern social environment and the exchange has been further requirements, expanding the exchange of public space, improve the environment of public life, communication channels and the quality of life and style. Art for public speaking has been integrated to form a world for all, an indispensable cultural welfare [3].

Integrated arts and social humanistic thoughts, social and economic life is closely related, is one of the most advanced creative industries in visual art, it involves the visual cultural philosophy, values, the image of the city, the art of ideological trends, social economy, and many other issues, construct and reflect the relationship between human and environment in the form of art expression, exploring the new orientation of the relationship between art and city, art and the public, art and society from the perspective of experiment with the artistic language[4]. With the development of modern painting, sculpture, architecture and the development of contemporary public space, has brought the new development of city spirit culture, under the background of the "big art" concept, the comprehensive art has become a new carrier to build the contemporary urban culture, it combines the traditional form of art and equipment, landscape, public art, multimedia art and other forms, Bridge medium with contemporary composite materials, to construct a new visual culture phenomenon [5]. New ways of

*Sponsor: Humanities and Social Sciences by the Ministry of Education of China (12YJA760068) information communication, multimedia communication, and the existence of network space, makes the comprehensive art beyond the simple physical space of the form construction, more shows a kind of social behavior under the projection of spiritual consciousness, it avoids the problem of the boundary thinning of the traditional art discipline, has a strong experimental [6].

\section{EXPERIMENTAL RESULTS DEMONSTRATING TEACHING AND SOCIAL COOPERATION}

How to operate an international we have the most modern standards of human civilization forward-looking ideas and expectations into the city for the logo, turned into a symbol, turned into a city's image voice, which is the real significance of promotion for comprehensive Arts into the culture, showing the city people's dreams and attitude toward life, as well as enhance the city's history, and cultural values of the shape will be the construction of the city's most distinctive physical and cultural expression [7].

2011, Academy of Fine Arts in Northeast Normal University, Jilin Architecture and Civil Engineering Institute, Northeast Electric Power Design Institute, Jilin Expressway Group Co., ltd., the sculpture and landscape design projects along the road of common creation. Relying on Academy of Fine Arts, Northeast Normal University, more than thirty years of accumulated solid strength, cross integration of resources of sculpture, environmental art design and visual communication design, relying on a sound structure, full of pioneering spirit of the teacher resources, under the effort of all the professional students, these works of art have been standing on both sides of the highway along the Ji-Chao.

Highway of development is culture. We can see the beautiful scenery along the highway, economic development, the city the best memories and associations, the teaching content and research, engineering, social application of practice in close contact with professional qualities to guide students to sort out the cultural context in Jilin City, the regional economy and the arts to promote the city's comprehensive investigation, emphasized and affirmed the original public art and their own spirituality and culture and social integration in the teaching does not lightly deny the student's initial program, the program reveals the full personality of the design ideas to be sure, to stimulate their 
own potential mining, to encourage students to display their personality. Works is shown in "Fig. 1" and "Fig. 2".
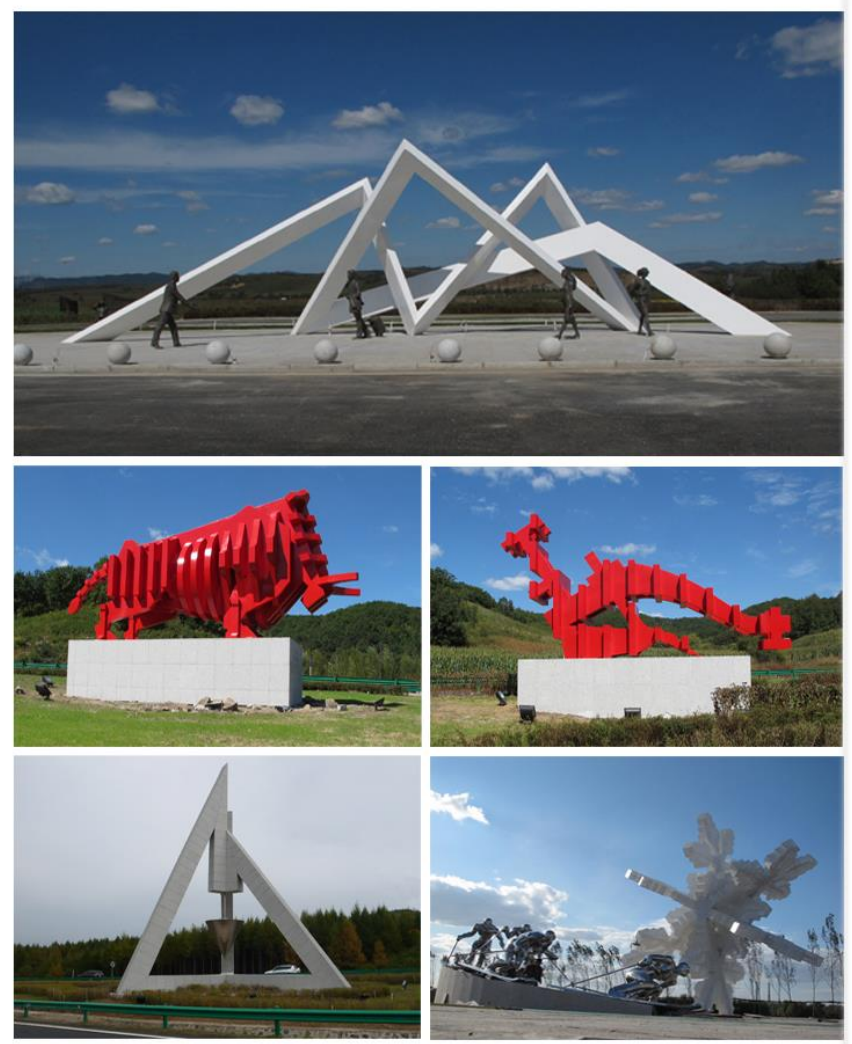

Fig. 1. Arts of experimental teaching-sculpture along the highway
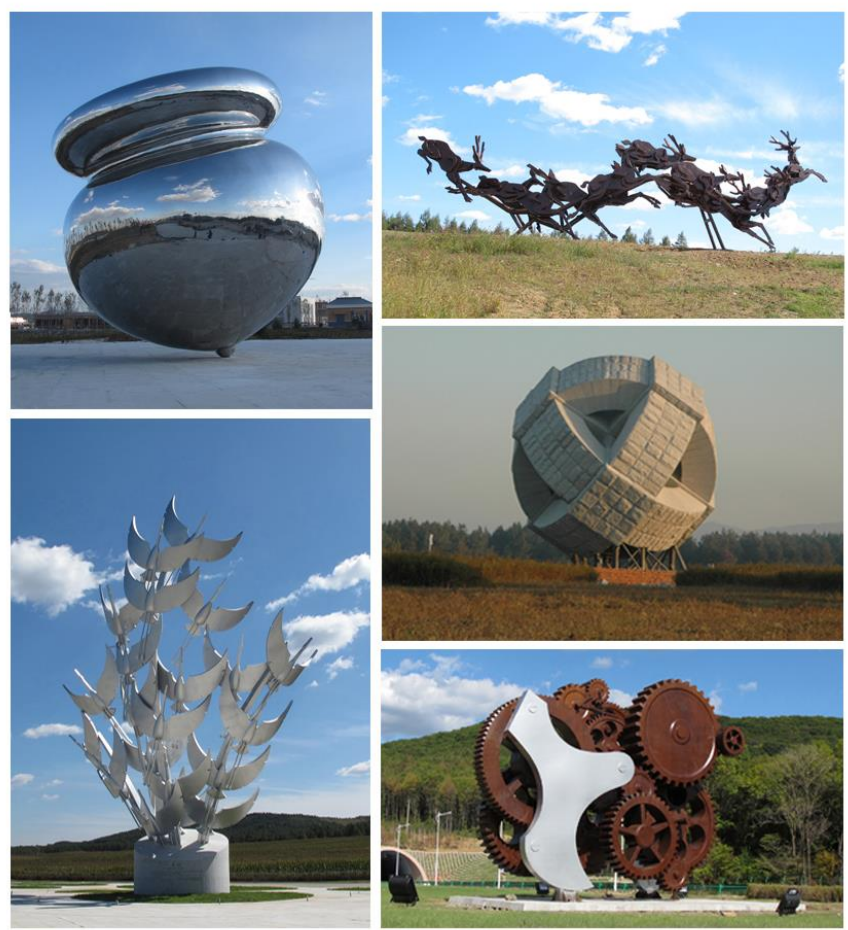

Fig. 2. Arts of experimental teaching-sculpture along the highway
In the project, the content of experiment teaching is closely related to the practice of scientific research, engineering and social application, combined with professional characteristics, to guide students to the cultural context of Jilin city, research on the regional economy and comprehensive art promotion of the whole city, emphasize and affirm the originality and spirit of the comprehensive art, and combined with social culture. In teaching is not lightly deny the students initial program, the program reveals the full personality of the design ideas to be sure, tap their own potential to stimulate and encourage students to display their personality. Emphasis students basic skills on the modeling, strengthen application, design, innovative teaching experiment, students build the knowledge, ability, quality of comprehensive and coordinated development of the experimental teaching system, fully mobilize the independent innovation ability and personality of students the art of creative thinking; in the "open" experimental teaching model on, students focus on creative thinking, integrated literacy and professional capabilities, to enable students to master basic skills to enhance application design ideas into the practical ability [8], [9], [10].

Relying on Northeast Normal University, Academy of Fine Arts with thirty years of accumulated strength of the sculpture, environmental art and design, visual communication design disciplines, in the efforts of the whole, these works of art have been standing in the highway exit, it is not only high-quality experimental Northeast Normal University Institute of Fine Arts to explore the results of education reform, it is unique in Jilin City landscape landmark works of art, so that each passing friend in Jilin City, felt history as well as geographical, cultural symbols, to appreciate modern art and high-speed movement, spread Jilin People's memories and the culture of modern life .

\section{ARTS TEACHING SYSTEM AND MODE OF EXPERIMENTAL CONSTRUCTION}

"Fig. 3" shows the experimental teaching of experimental procedures in this work.

Relying on comprehensive, multidisciplinary university resources, Art Academy of Fine explicitly integrated experimental teaching system, positioned to develop a deep cultural heritage, integrated innovation and professional quality of teachers of modern artistic talents, highlighting the "art and science, art and education "the two combined. Experimental teaching philosophy of "unity of knowledge, both are teaching and learning." "Knowledge and Action" refers to the artistic integration of literacy and professional skills, theoretical knowledge and practical ability of the fusion; "both teaching and learning" refers to students' learning ability and professional capacities to promote the teaching, practice, study, research, summarize and explain the capabilities and capacities to promote [11], [12]. 

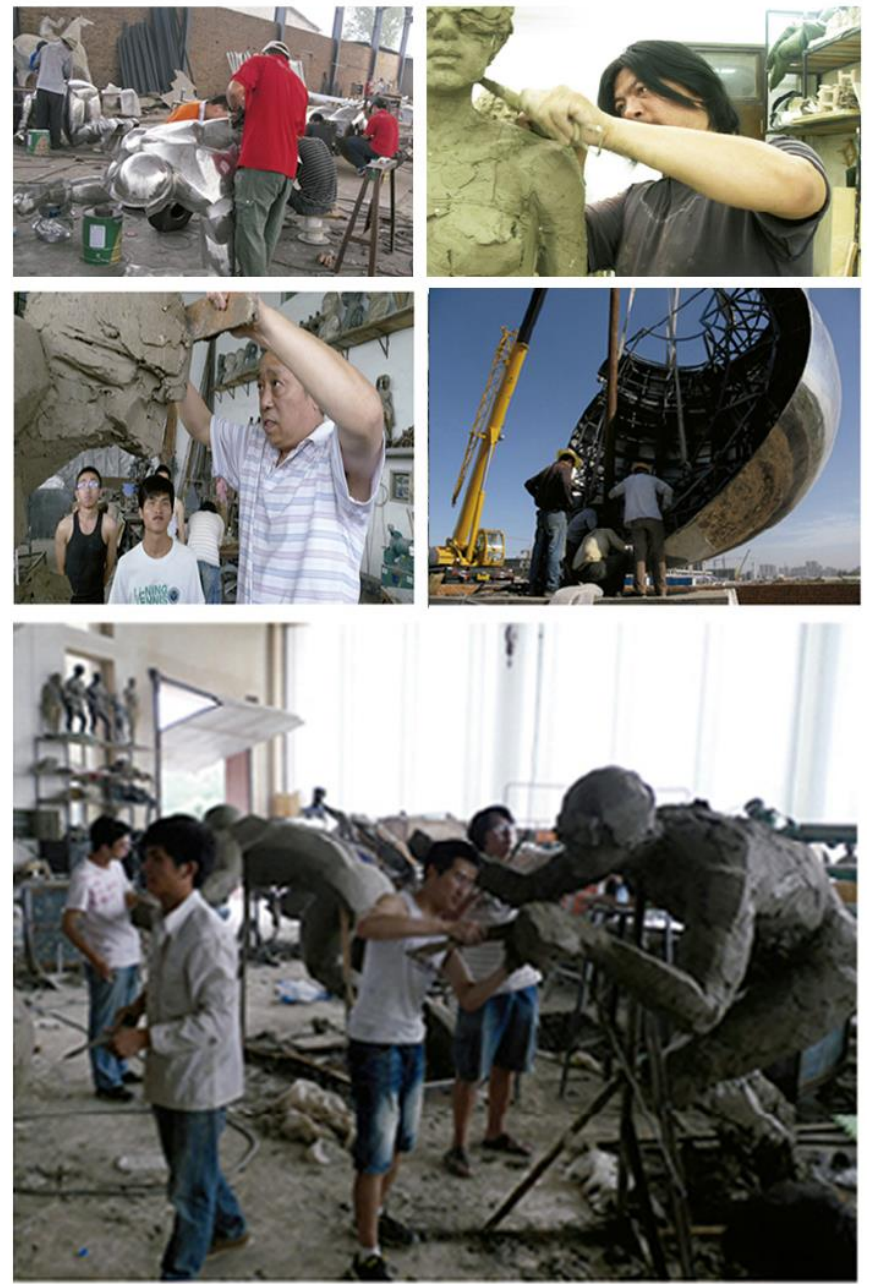

Fig. 3. Arts of experimental teaching-sculpture along the highway

\section{A. Establish a Comprehensive Art Experimental Teaching System}

The experiment teaching system consists of three modules, modeling and performance module, design and application module, teacher quality and skill, it also forms the main frame of experimental teaching of basic experiment, comprehensive experiment teaching and innovative experiment teaching. The specific experimental courses and experimental project into the module, according to the nature of the curriculum and the training objectives, the course of each module is composed of three types of basic, comprehensive and innovative experiments, fully implement the different levels in the experimental subject selection, research, creative achievements in teaching reflection, create a free space for students to "experience creation and sublimation"[13-15]. Combination of experimental teaching and basic art education, combining with personal creation, combining with social practice, three combination of experimental teaching principles in the selection of topics, creative research, the results of reflection and other teaching aspects to be fully implemented, to ensure that the theory and practice of the experimental teaching activities can be effectively integrated and communicated, breaking discipline barriers, to realize the cross complementation of various professional disciplines.

The establishment of comprehensive art experiment teaching system, make the experiment teaching carry out the unified planning, gradually strengthen the basic ability of the professional students, comprehensive ability and research innovation ability, the whole system is characterized by flexibility and flexibility, which is in line with the characteristics of professional and comprehensive art education talents.

\section{B. Practice Teaching Mode of Learning, Researching and Creating Integration}

The development of experiment teaching emphasizes the combination of experimental teaching and basic art education, combined with personal creation, the principle of experimental teaching combined with social practice, planning, setting up, directing and coordinating the experiment course, focus on teaching objectives, breaking the boundaries of the profession and the mode of traditional fine arts education, to realize the cross complementation of various professional disciplines.

"Learning" refers to the learning of professional knowledge and skills, through the experiment of art, made the abstract theory is visualized, cultivating students' autonomous learning ability, so as to form a more complete knowledge system, teachers and students are the main body of practice, in the experiment teaching, the students are the core, initiate and accumulate knowledge in experiment. "Research" refers to the experiment by means of inquiry, the research process of experience, cognition and reflection, inspire students to think in the experiment. "Innovation" refers to the involvement of the project through the project, inspire students to create enthusiasm, cultivating students' creative thinking and creativity, make the students research in the study, create in the study, and improve in creation.

The characteristic of comprehensive art is mainly reflected in its practicality and innovation, this practice and innovation is reflected in the professional skills and professional level, must be reflected in the teaching work, The first is the innovation of talent training mode, change the traditional knowledge and skill based design talents training mode, transformed into practical ability as the main body, combination of theoretical and innovative talents training mode. However, a large number of Arts Colleges and universities curriculum setting and training mode are followed for many years, can not adapt to the professional development of the quality of talent requirements, the drawbacks of its aging and conservative gradually revealed, The gap between the training mode and the demand of social development will be caused by the backwardness of the training mode, more can not play the role of leading and creating social needs. The comprehensive art should reflect its leading edge, education should innovate in the mode of personnel training and teaching methods, do not only be able to better adapt to employment, should also be able to lead the development direction of the industry. 


\section{CONCLUSION}

For many years, Academy of Fine Arts, Northeast Normal University integrated with the market and combined with production and study, try from a different point of view, a combination of knowledge to explore social issues, to improve participation in social practice and self-learning ability, combine design teaching and theoretical research, promoting the healthy and stable development of subject construction, practice has proved that only the school model of the combination of production, learning and research, learning and research, the development of art disciplines can be a strong guarantee.

In today's fast urbanization process, the comprehensive Arts as with other design professionals have unprecedented opportunities for the design space, in the integrated arts training process, which allows students to participate in their own competitive bidding program, in the competition continue to learn and improve, making the teaching of content in creativity, quality, efficiency, feasibility may be raised. Participate in social market competition mechanism, from the failure to summarize problems, confidence in the success and promote the improvement of academic teaching institutions, in practice, teaching, research and practice to expand the size and ability to form a combination of features and professional, In the competition continue to learn and improve, making the teaching of content in the creativity, quality, efficiency, feasibility may be raised.

\section{ACKNOWLEDGMENT}

The authors gratefully thank the financial support by Research Project in Humanities and Social Sciences by the Ministry of Education of China (12YJA760068).

\section{REFERENCES}

[1] Faiyetole, Ayodele A, Takahashi Yuki, Eley Serena, Art space education system and the scientific but people-oriented edution, International Conference on Instrumentation, Measurement, Circuits and Systems, Vol.1: Instrumentation, Measurement, Circuits and Systems, 2011, pp. 117-120.

[2] L. Beudert, Arts Teacher Education, International Encyclopedia of Education (Third Edition), 2010, pp. 695-701.

[3] Interior landscape design applying to environmental art education, Journal of Korean Society for Plants, People and Environment, vol.7, No.3, 2004.

[4] Zhenyu Jiao, Yongbo Lai. The values deconstruction of Peopleoriented contemporary education (Example of Nanyang Polytechnic), 2010 International Conference on Education and Sports Education, Vol.1, 2010, pp.311-314.

[5] Dave Donahue, Jennifer Stuart, Working towards balance: Arts integration in pre-service teacher education in an era of standardization, Teaching and Teacher Education, vol. 2, 2008, pp. 343-355.

[6] Klein Adrienne, The Art/Science Curriculum in the Classroom and in the Cloud, LEONARDO, vol.48, No.5, 2015, pp.56-58.

[7] C.M.Thompson, L.Bresler, T.E.Costantino, Curriculum in the Arts, International Encyclopedia of Education (Third Edition), 2010, pp. 423-427.

[8] Alan Peacock, The Arts and Economic Policy Review Article, Handbook on the Economics of Art and Culture, 2006, pp. 1123-1140.
[9] Graaff E, Kolmos A, Characteristics of Problem Based Learning. International Journal of Engineering Education, vol.19, No.5, 2003, pp.657-662.

[10] Meral Per, Aylin Beyoğlu, Personality types of students who study at the departments of numeric, verbal and fine arts in education faculties, Procedia - Social and Behavioral Sciences, vol. 12, 2011, pp. 242-247.

[11] Rieger Kendra, Chernomas Wanda, McMillan Diana, The effectiveness and experience of arts-based pedagogy among undergraduate nursing students: a comprehensive systematic review protocol, JBI database of systematic reviews and implementation reports, vol.48, No.5, pp. 101-24, 2015.

[12] Park Jeong-Ae, Paradigm Shift in Art History Education:ViewerCentered Education, Art History, vol.31, pp. 209-235, 2016.

[13] Hayton Ruth, Annette Haste Polly, Promoting Diversity in Creative Art Education: The Case of Fine Art at Goldsmiths, University of London, british journal of sociology of education, vol 37, pp. 1258, 2015.

[14] Ulger kani, the creative training in the visual arts education, thinking skills and creativity, vol.19, pp. 73-87, 2016.

[15] Gulliksen Marte S, Hjardemaal Finn R, Choosing Content and Methods: Focus Group Interviews with Faculty Teachers in Norwegian Pre-Service Subject Teacher Education in Design, Art, and Crafts. Scandinavian journal of educational research, vol.60, No.1, pp. 1-19, 2016 